\title{
Entre las industrias, la educación y el campo: Historia local de la subdelegación de Marruecos, al sur poniente de Santiago entre 1927 y 1954
}

Between industries, education and the countryside: Local history of the Marruecos sub-delegation, South West of Santiago between 1927 and 1954

\author{
Oscar Alejandro RIQUELME GÁLVEZ \\ Universidad de Chile \\ oscarriquelme@ug.uchile.cl
}

\section{Resumen}

En la periferia semi rural del Gran Santiago al sur poniente se ubicaba la antigua subdelegación de Marruecos (actual comuna de Padre Hurtado). Previo al despertar campesino de la reforma agraria, la localidad, y específicamente, la escuela " $\mathrm{N}{ }^{\circ} 4$ " (actual República Argentina), emplazada dentro del fundo Santa Cruz, representaron un punto neurálgico de resistencia a la situación de pobreza premoderna del campesinado. Dentro de la escuela se conservan 148 libros (principalmente registros escolares) que, como fuentes inéditas, en conjunto con otras fuentes locales (prensa, testimonios, planos, fotografías) permiten elaborar una aproximación histórica local, desde un enfoque cultural-social, a un período marcado por una industrialización dirigida por el Estado que cambió la metamorfosis de localidades rurales vecinas a la capital como Maipú y San Bernardo, pero que fue escasamente dinámica para el espacio de estudio propuesto. Así pues, este estudio explora la creación de pequeños espacios alrededor de la estación ferroviaria, su habitar y las condiciones para resignificarlos ritualmente. La penuria acompañada de la servidumbre hacendal y el patriotismo imaginado de las festividades de la localidad movieron fuertemente la vida cotidiana de la subdelegación rural, y la escuela, en un contexto de apertura local, sirvió como catalizadora en ciertos momentos de un espacio de encuentro común.

Palabras clave: Marruecos; Escuela $\mathrm{N}^{\circ} 278-\mathrm{N}^{\circ} 4$; Pobreza campesina; Historia local. 


\begin{abstract}
In the semi-rural periphery of Greater Santiago to the south west was located the old sub-delegation of Marruecos (current municipality of Padre Hurtado). Prior to the peasant awakening of the agrarian reform, the town, and specifically, the school "N4" (current República Argentina), located within the Santa Cruz hacienda, represented a neuralgic point of resistance to the situation of pre-modern poverty of the peasantry. Inside the school, 148 books are kept (mainly school records) that, as unpublished sources, together with other local sources (press, testimonies, plans, photographs) allow the elaboration of a local historical approach, from a culturalsocial perspective, towards a period marked by an industrialization directed by the State that charged the metamorphosis of rural localities neighboring the capital, such as Maipú and San Bernardo, but which was hardly dynamic for the proposed study space. Thus, this study explores the creation of small spaces around the railway station, their inhabitation, and the conditions to ritually re-signify them. The hardship accompanied by the ranch servitude and the imagined patriotism of the local festivities strongly moved the daily life of the rural subdelegation, and the school, in a context of local openness, served as a catalyst in certain moments of a common metting space.
\end{abstract}

Keywords: Marruecos; School $N^{\circ} 278-\mathrm{N}^{\circ} 4$; Rural poverty; Local history.

\title{
1. Introducción
}

En la periferia semi rural del Gran Santiago al sur poniente se ubica la comuna de Padre Hurtado. Su escasa urbanización representa un puente entre el mundo industrial y del sector de servicios expresado en la comuna vecina de Maipú (punto de entrada a la gran urbe), y la extensa zona rural de Padre Hurtado y la comuna vecina de Peñaflor (punto de entrada a la Cordillera de la Costa). En el casco histórico de la comuna la pequeña zona urbana actualmente no supera la veintena de cuadras de largo (y quince de ancho) y todavía mantiene una ausencia arquitectónica de instituciones públicas y privadas, pero contrastan con el potencial desarrollo inmobiliario de la ciudad satélite del barrio "Laguna del Sol" y el continuo crecimiento urbano del sector de los "Los Silos", que posicionan cada vez más a la comuna como un lugar de descanso y eje de crecimiento de la gran capital. Por lo mismo, son muy pocos los espacios que rememoran el largo período decimonónico y rural de la comuna, ex subdelegación de la comuna de Peñaflor.

En ese contexto, la escuela República Argentina (ex escuela "N²78" o "Escuela Mixta Rural de Santa Cruz" desde 1916 hasta 1943, y ex escuela "N4" 
desde 1943 hasta 1961), emplazada actualmente en la calle San Francisco de Borja, es por excelencia uno de los espacios más icónicos de la comuna. Dicho establecimiento educacional permite reconstruir históricamente el espacio en clave localista no solo porque conserva parte de su arquitectura rural que data del 6 de noviembre de 1916, sino porque, más importante aún, la escuela conserva 148 libros, principalmente registros escolares que abarcan desde el año 1937 hasta el 20131. En 2017 cuando trabajé con la Unidad de Cultura de la Municipalidad de Padre Hurtado me encargué de digitalizar y restaurar dichos libros que se estaban deteriorando en las bodegas de la escuela. Estos registros son de una importancia inusitada por la calidad de su contenido, especialmente por sus secciones "vida escolar", "visitas" y "registros de matrícula", necesarios para reconstruir la historia de la localidad, que, hasta el día de hoy, solo ha sido abordada desde una aproximación política por el historiador Hernán Bustos Valdivia en 1997.

Las fuentes de índole institucional nos permiten saber que el 22 de diciembre de 1891 se creó la municipalidad de Peñaflor comprendiendo las subdelegaciones de Santa Cruz (actual Padre Hurtado), La Esperanza y Peñaflor de la Victoria, con los límites fijados por el decreto de 23 de agosto de 18752. Por decreto del presidente Montt, el 20 de febrero de 1909 se creó la comuna de Santa Cruz de la Victoria, del departamento de la Victoria. Santa Cruz, a partir del 27 de septiembre de 1940, dejó de pertenecer a la provincia de Santiago, pasando a depender de la provincia de Talagante (Bustos Valdivia, 1997: 161). La comuna de Santa Cruz estaba compuesta principalmente por los fundos El Bosque y Santa Ana de Chena por el norte, y El Descanso por el sur, y existió desde el 20 de febrero de 1909 hasta el 30 de diciembre de 1927, para luego volver a ser subdelegación de Peñaflor bajo el nombre de "Marruecos", hasta que el viernes 27 de agosto de 1954 por decreto de ley 11.573 es cambiado al nombre de "Padre Hurtado"3.

Por otro lado, los libros de registro escolar visibilizan nombres que por lo común caen en el olvido y emociones que expresan penurias de la vida cotidiana y patriotismos imaginados. Esto nos abre la interrogante del papel que tuvo la escuela en la subdelegación rural, por su ubicación estratégica cercana a importantes puntos de conectividad y por ser una de las pocas edificaciones en toda la localidad.

Por ende, este estudio representa en gran parte una sistematización de estas fuentes inéditas, que en conjunto con otras fuentes locales (prensa, testimonios,

\footnotetext{
1 En palabras del director de la escuela: "los registros más antiguos se perdieron y se quemaron con un incendio que azotó a la escuela".

2 "Boletín de las Leyes i Decretos del Gobierno. Decreto N²297 Creación de Municipalidades, 1891", 321, 322. En Biblioteca Nacional de Chile.

3 Igual nombre tomó la Estación de Ferrocarriles del Estado. La subdelegación de Padre Hurtado debió esperar hasta el 22 de diciembre de 1992 para constituirse como comuna con una población de 28.861 habitantes. Decretos en el periódico local "Padre Hurtado Nuestra Comuna". Año 1, N², 15 de mayo de 1993. En Archivo Unidad de Cultura Municipalidad de Padre Hurtado.
} 
planos, fotografías), permiten desarrollar una aproximación histórica local desde un enfoque cultural-social, a un período de industrialización dirigida por el Estado que cambió la metamorfosis de localidades rurales vecinas a la capital como Maipú y San Bernardo, pero que fue escasamente dinámica para el espacio de estudio.

Así pues, este estudio busca comenzar en 1927 cuando desaparece la comuna de Santa Cruz y cambia su denominación al nombre de "Marruecos", mientras que su término se concreta en 1954 cuando adquiere su denominación contemporánea de "Padre Hurtado". En ese marco temporal, la exploración histórica de la localidad es desarrollada en dos niveles: por un lado, enfocado en la subdelegación en su zona rural y casco histórico, y, por otro lado, enfocado en las particularidades presentadas en la escuela " $\mathrm{N}^{\circ} 278 /$ " $\mathrm{N}^{\circ} 04$ ".

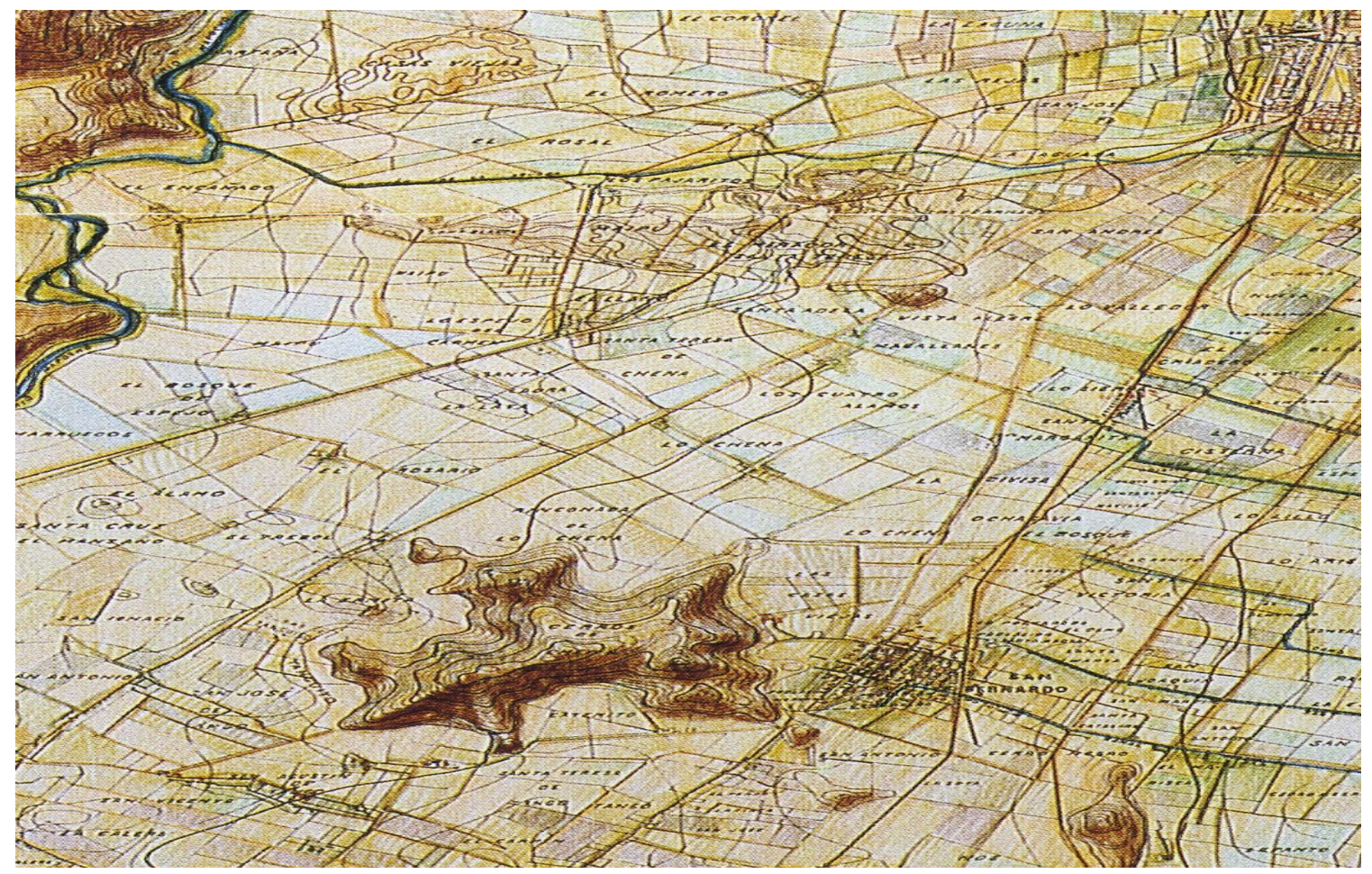

A la izquierda del mapa: Las haciendas de Marruecos (hoy Padre Hurtado), y las pequeñas localidades rurales de Maipú y San Bernardo en las periferias de Santiago. Plano intervenido y modificado por el autor. Plano original de Rengifo (1901)4.

\section{Entre las industrias y el campo}

Hacia el poniente del valle del Maipo, desplazado por la parte sur de Santiago uniéndose con el valle del Mapocho, se encontraban numerosos pequeños poblados.

${ }_{4}$ Rengifo, Agustín (1901). Santiago i sus alrededores (mapa). Santiago. En Memoria Chilena (sitio web de la Biblioteca Nacional de Chile), MAP-1902-REN-MCH-00. Recuperado de http://www.memoriachilena.cl//temas/documento detalle.asp?id=MC0037178. 
Los principales poblados estaban conectados por el camino de Santiago a Melipilla que, cubierto por una oscura alfombra de asfalto, era recorrido a diario por los caminantes, carretones de bueyes, carruajeros, y uno que otro vehículo motorizado. Entre Maipú y Peñaflor se situaba el pequeño poblado de Marruecos (ex Santa Cruz y actual Padre Hurtado). Solo el camino vecinal con salida al Camino a Melipilla, de dos leguas aproximadamente, conectaba a Marruecos con la localidad de Peñaflor, por lo que el principal eje de conectividad lo detentaba la estación de ferrocarril de Marruecos que se encontraba en la banda inferior del río Mapocho, a $430 \mathrm{~m}$ de altitud, a 7 kilómetros de la estación de Maipú y a 6 kilómetros de la estación de Malloco (Bustos Valdivia, 1997: 58,61). A unas cuantas casas situadas a un costado del camino a Melipilla y la estación de ferrocarril se situaba el Caserío de Santa Cruz. Su dueño, Ernesto Valdés García Huidobro, era agricultor, director de la Sociedad Explotadora de Comercio, también alcalde de la antigua comuna de Santa Cruz de La Victoria durante 18 años y también estuvo a cargo de la alcaldía de Peñaflor entre 1938-1941 (Bustos Valdivia, 1997: 181). Pero el fundo de Santa Cruz no era el más importante de la subdelegación. Cerca se encontraba el fundo de Marruecos que tenía 423 hectáreas de terreno regado y se encontraba en los alrededores de la estación ferroviaria del mismo nombre5. La existencia de dicho ferrocarril permitiría una estrategia multiproductiva en dichos fundos. Esto puede notarse si nos fijamos en el propietario del fundo Marruecos, Alberto Tagle Ruiz: productor de leche, pasto, trigo, chacarería y multiplicación de semillas, además de tener modernos establos y silos, y 35 casas de adobe con techos de paja y cañas de maíz recubiertas de barro para los inquilinos (Bengoa, 2015: 57). Así, en 1927, el nombre de la hacienda se hizo extensivo a toda la localidad.

Por otro lado, el municipio de Peñaflor estaba en sintonía con el discurso modernista que se enfocaba en la preocupación de la higiene, el embellecimiento, la pavimentación de las carreteras y construcción de parques, "que son las síntesis de las preocupaciones actuales, sino también de la economía de la Comuna"6. Inclusive la prensa local se preocupaba por dar a conocer los sucesos tanto del acontecer nacional como internacional, como el 17 de septiembre de 1942: "El 132 aniversario de nuestra independencia encuentra a todos los chilenos presenciando el cuadro universal más horroroso. Dos ideologías, dos postulados luchan por la supremacía del mundo"7.

Sin embargo, de las tres localidades que conformaban la comuna de Peñaflor (Peñaflor, Malloco y Marruecos), era Marruecos la menos urbanizada. El historiador

\footnotetext{
${ }_{5}^{5}$ En "Diccionario Jeográfico de Chile por Luis Riso Patron", 1924, 532. Biblioteca Nacional de Chile.

6 "La Voz de Peñaflor", Año 1, Núm. 2, 6 de abril de 1935, 5. Archivo Unidad de Cultura de la Municipalidad de Padre Hurtado.

7 "El Peñaflor", 17 de septiembre de 1942. Archivo Unidad de Cultura de la Municipalidad de Padre Hurtado.
} 
Hernán Bustos ha investigado que para 1920, la localidad de Marruecos contaba con solo 23 teléfonos y recién en 1928 llegó la energía eléctrica y servicios de cañería de agua potable. En el mismo año, en un terreno cedido por el vecino Manuel Covarrubias se construyó la plaza de la localidad, en la bifurcación del Camino a Valparaíso y Camino a Melipilla. Y a diferencia de Peñaflor y Malloco, a Marruecos no llegaron los carros de sangre, pero sí a partir de 1931, comenzó a funcionar el servicio de góndolas de las Líneas Rurales Unidas. Esto fue fundamental para facilitar las conexiones de la localidad rural con los recorridos a Maipú-Cerrillos y Santiago (en la terminal Plaza Argentina frente a Estación Central) por un lado, y Malloco y Peñaflor por el otro (Bustos Valdivia, 1997: 65, 92, 103).

La actividad comercial dentro de la localidad se reducía a ocho despachos de licores, una carnicería y una herrería, mientras que la industria artesanal se reducía a la "Panadería Marruecos" que se ubicaba en una pequeña casona ubicada en el camino a Melipilla (Bustos Valdivia, 1997: 84, 87). Pero la industrialización dirigida por el Estado durante la década de los 1940 promovió la creación de numerosas empresas mixtas y privadas a lo largo del camino a Melipilla entre Maipú y Cerrillos formándose uno de los corredores industriales más grandes del país. Inevitablemente, como Marruecos estaba solo a unos cuantos kilómetros de la naciente metamorfosis urbana de Maipú, la intervención estatal generó lo suyo en la localidad con el levantamiento de una carbonera para la extracción de carbón que era usado tanto en el ferrocarril que iba a San Antonio como para alimentar a la capital con esta materia prima. Gracias a su excelente ubicación en relación a los caminos a Santiago y Valparaíso, se vio beneficiado en la década de 1950 y 1960 con la instalación de empresas industriales como Cristalerías Chile, Lota Green y ProAlim (Bustos Valdivia, 1997: 89). Este fenómeno es realmente importante puesto que marcó la llegada de uno de los primeros elementos realmente modernizadores y urbanos al casco central de la villa.

La historiadora Gillian Darley alude a que "una fábrica no es simplemente una máquina bien engrasada ni un escenario arquitectónico, sino una compleja estructura social. [...] En resumen, las fábricas son el fenómeno más cercano a la vida urbana" (Darley, 2010: 133). Con la creación de micro paisajes y un prematuro paisaje industrial en los contornos de la línea ferroviaria, el camino Melipilla se convirtió en un punto neurálgico para la expansión industrial en el suroeste de Santiago y muchas de estas empresas, apelando a que "la vivienda casi siempre estaba vinculada al trabajo, como en las haciendas de los terratenientes" (Darley, 2010: 76), se dedicaron a crear pequeños barrios para sus trabajadores que eran reclutados tanto dentro de la misma comunidad rural como fuera de ella. Muy en boga con el fenómeno de los industriales progresistas que ya estaban emprendiendo nuevos modelos de asentamientos fabriles y experimentos sociales en la comuna de Maipú, como INSA y Pizarreño, y en la comuna de Peñaflor con Bata. 
No obstante, la localidad era predominantemente rural (en un 97\%), no urbana, lo que se encontró con más dificultades de transformación y modernización, que posibilidades. José Bengoa afirma que el "eje de la acumulación de capitales" al concentrarse en la industria hizo que la agricultura, de alguna manera, volviera a recuperar su relevancia "dejándola relativamente igual y a las haciendas y hacendados tranquilos" (Bengoa, 2015: 14). Las decisiones tomadas durante los primeros años del gobierno de Pedro Aguirre Cerda tuvieron como consecuencia que en el Valle Central de Chile se prolongase la vida al sistema de haciendas por treinta años condenando a una generación completa de campesinos a seguir viviendo en una situación de "ruralidad no transformada": semi esclavitud, servidumbre, pago en especies, ausencia de salarios en metálico (Bengoa, 2015: 224).

En ese contexto, Miguel Jesús Verdugo Araya nació el treinta de marzo de 1942 en Marruecos. Nació en una época turbulenta para el país en plena expansión industrial liderada por los gobiernos radicales y en una tensa situación internacional producida por la Segunda Guerra Mundial. Hoy con 79 años, Verdugo es un testimoniante de cómo fue vivir en la localidad de Marruecos a mediados del siglo XX:

Yo soy nacido y criado en el fundo Las Compuertas que ahora ya no existe. Entonces empecé a ver prácticamente aquí todos como nos conocíamos porque éramos tan pocos que nos conocíamos porque yo visitaba casa por casa con mi negocio. Después cuando esto empezó a poblarse, que lo primero que empezó a poblarse fue Santa Rosa, hubo cambios en la estructura para dentro cuando empezó a construirse Cristal Chile, se construyó porque había un solo galpón, se construyó por los años sesenta, sesenta y cinco más o menos, empezó a expandirse y empezó a crecer el entorno. Para el fundo Santa Cruz, había quince, veinte casas, entonces esa transformación nos empezó a cambiar la vida a todos... Yo fui a la escuela [N이 solo cuatro años, hasta cuarto año, y haber llegado a esa instancia y trabajando, porque yo empecé a los doce años a trabajar, para mí fue una explosión ver como veía gente extraña a lo que no conocía, porque yo conocía a casi toda la gente aquí, todos me conocían a mí también, la reforma agraria empezó a entregar parcela, hay mucha gente que todavía queda de aquella época. Para mí esas transformaciones de aquel pueblo, empezaron las parcelaciones, la expansión de acá del pueblo, de acá de 50 personas que éramos por ahí, del 73 éramos más de mil, uno estaba acostumbrado a llegar un fundo y encontrarse con esas personas. A los 12 años ya estaba trabajando en el fundo para pagar la obligación del fundo que alguien tenía que trabajar [...] para que le dieran casa. Me 
daban la leche, el pan, el almuerzo, todos eso había que ir a buscar a las llaverías que les llamaban antes. Entonces esta parte geográficamente fue unos de los puntos neurálgicos porque nosotros la verdad siempre fuimos el patio trasero de Peñaflor, entonces después ver esto dignificó de que estábamos creciendo, de ahí por el año 60 para adelante empezamos a crecer y ver otras historias... en el 63 teníamos un lugar de encuentro, que nos empezamos a juntar alrededor del pueblo que era la estación ferroviaria que está por la calle Julio Covarrubias para allá. Cuando nos juntábamos después éramos sesenta personas. Ver el año 65 como se llenaba un tren con gente, que eran los paseos obligados que nos hacían el cura de aquí a Cartagena, de ahí para delante esto empezó a transformarses.

En una zona con una baja densidad poblacional, pero con las condiciones necesarias para generar espacios de relación publica y comunitarias, mayores son las probabilidades de desarrollar una identidad cultural de tipo local, pues los habitantes de una comunidad pueden conocerse más fácilmente entre sí, cuanto más baja es la cantidad de personas, más alto puede ser el nivel de interacción y comunicación entre los individuos. Además, la vida y el trabajo de los individuos poseen lazos en común que mantienen a través de las generaciones elementos de una vida rural, y en mucha menor medida, industrial (Wirth, 1963: 7, 9). Es muy propio de este tipo de localidad que la vida privada y pública esté en constante interacción y produzca espacios como el que daba la escuela " $\mathrm{N}^{\mathrm{0}} 4$ " y la estación ferroviaria, huellas de una temprana sociedad folclórica rural, constituidos como espacios centrífugos de actos de celebración y reunión tal como relata Verdugo.

Empero, en las afueras de Santiago, uno de los elementos indispensables para la mantención de la "estructura tradicional del inquilinaje" fueron las misiones en las haciendas, en palabras de José Bengoa, impregnadas de "un catolicismo barroco, lleno de imágenes de cristos sangrantes y vírgenes llorosas" (Bengoa, 2015: 47, 225). El propietario Alberto Tagle, interesado en que los vecinos de Marruecos contaran con un servicio religioso más cercano, ya que la iglesia más cercana se encontraba fuera de la subdelegación, en Malloco, decidió donar un terreno cercano a la Plaza para construir una iglesia. Los planos fueron hechos por su hijo, el arquitecto Ignacio Tagle Valdés. Contiguo a este templo, Alberto Tagle donó varias hectáreas del fundo Marruecos para construir, con mano peonal, un convento que fue aprovechado con la llegada del noviciado en 1938, que antes se encontraba en

8 Entrevistado por este autor en 2017. Miguel Jesús Verdugo Araya, Alberto Hurtado, avenida San Pedro 207. Archivo Oral Municipalidad de Padre Hurtado: AOMPH10. 
Chillán y que luego del terremoto, debió trasladarse con un seminario más cercano a Santiago ${ }^{9}$.

Fue así como los Padres de la Compañía de Jesús se hicieron cargo del servicio de la Parroquia San Ignacio de Loyola, que comenzó a ser construida el 12 de marzo de 1940, siendo su primer párroco don Hernán Irarrázabal (Bustos Valdivia, 1997: 32). Dicho convento comenzó a adquirir una relevancia fundamental tanto por su actividad misional en la zona, como por la cantidad de actividades destinadas a los habitantes de la localidad (festividades y paseos). Durante el periodo de su construcción, Alberto Tagle falleció cediendo el fundo de 423 hectáreas a su hijo Manuel Tagle Valdés, ingeniero agrónomo de la Pontificia Universidad Católica, discípulo del jesuita Alberto Hurtado Cruchaga (futuro párroco del convento ${ }^{10}$ ), también a partir de 1938 regidor de la comuna de Peñaflor, también primer director de la 4⿳a - Compañía de Bomberos de Padre Hurtado fundada el 8 de diciembre de 1951, y más tarde diputado del Segundo Distrito por dos periodos por el Partido Conservador (Bustos Valdivia, 1997: 121, 132). Como puede notarse, las familias Tagle y Valdés ${ }^{11}$ fueron parte de una oligarquía terrateniente caracterizada por su condición de comerciantes-políticos, de "importancia económica indudable y de gran importancia social y política" (Bengoa, 2015: 57, 112). Pero también, estaban fuertemente identificados con el territorio que habitaban puesto que el 23 de julio de 1952 en la sesión municipal presidida por el alcalde José Lascar buscaron discutir la autonomía administrativa de la subdelegación:

Últimamente, en vísperas de las nuevas elecciones municipales, se han efectuado en el pueblo de Marruecos, que forma parte de la comuna de Peñaflor, reuniones de vecinos, y más recientemente, como lo transmitió la prensa, un cabildo abierto patrocinado por el regidor conservador tradicionalista don Manuel Tagle Valdés, de esta comuna, para tratar por todos los medios posibles se apruebe por el Congreso el proyecto por ellos presentado e incluido entre los que deben tratarse en la convocatoria y que separa este pueblo de escasos

\footnotetext{
9 En memorias: "Marruecos, por Regina Tagle de Riesco, 2007". Archivo Unidad de Cultura de la Municipalidad de Padre Hurtado.

10 La estadía en Marruecos le permitió acumular una experiencia que fue canalizada con posterioridad al ser parte de un importante movimiento antilatifundista de enormes proporciones con la formación de la Unión de Campesinos Cristianos, organización ligada a la Asociación Sindical de Chile.

11 El 22 de marzo de 1924 se nombró una Junta de Vecinos en representación de los propietarios, vecinos y comerciantes de Santa Cruz de la Victoria "con las mismas atribuciones y deberes que las municipalidades". Se nombró una junta de alcaldes: $1^{\circ} \mathrm{D}$. Mariano Flores, $2^{\circ}$ D. Carlos Caballero, $3^{\circ} \mathrm{D}$. Moises Diaz Valdes. "La Junta de Vecinos, presidida por el Sr. Flores, es la única Municipalidad legal a la cual deben reconocer todos los vecinos de la Comuna". "Edicto a los Propietarios, Vecinos y Comerciantes de Santa Cruz de la Victoria". 22 de mayo de 1924. Archivo Unidad de Cultura de la Municipalidad de Padre Hurtado.
} 
habitantes y de recursos insuficientes, de la actual comuna de Peñaflor, para formar una independiente y estado aún vigente el empréstito que afecta a toda la comuna" 12 .

La simbología identitaria que aportó la figura del padre Alberto Hurtado producto de haber visitado en persona la zona, dirigir misas, ser testigo del levantamiento del Centro de Espiritualidad Loyola y dirigir parte del trabajo social dentro de la localidad, sirvió para que su imagen fuera desarrollada como una invención simbólica inmaterial "desde arriba", desde la institucionalidad al cambiar el nombre de Marruecos por el de Padre Hurtado en 1954. Padre Hurtado se convirtió en una figura mitificada que funcionó y se hizo parte de una memoria peticionista de arraigo local donde autoridades buscaron la autonomía administrativa de Peñaflor. Dicho anhelo no se concretó hasta el 10 de octubre de 1994.

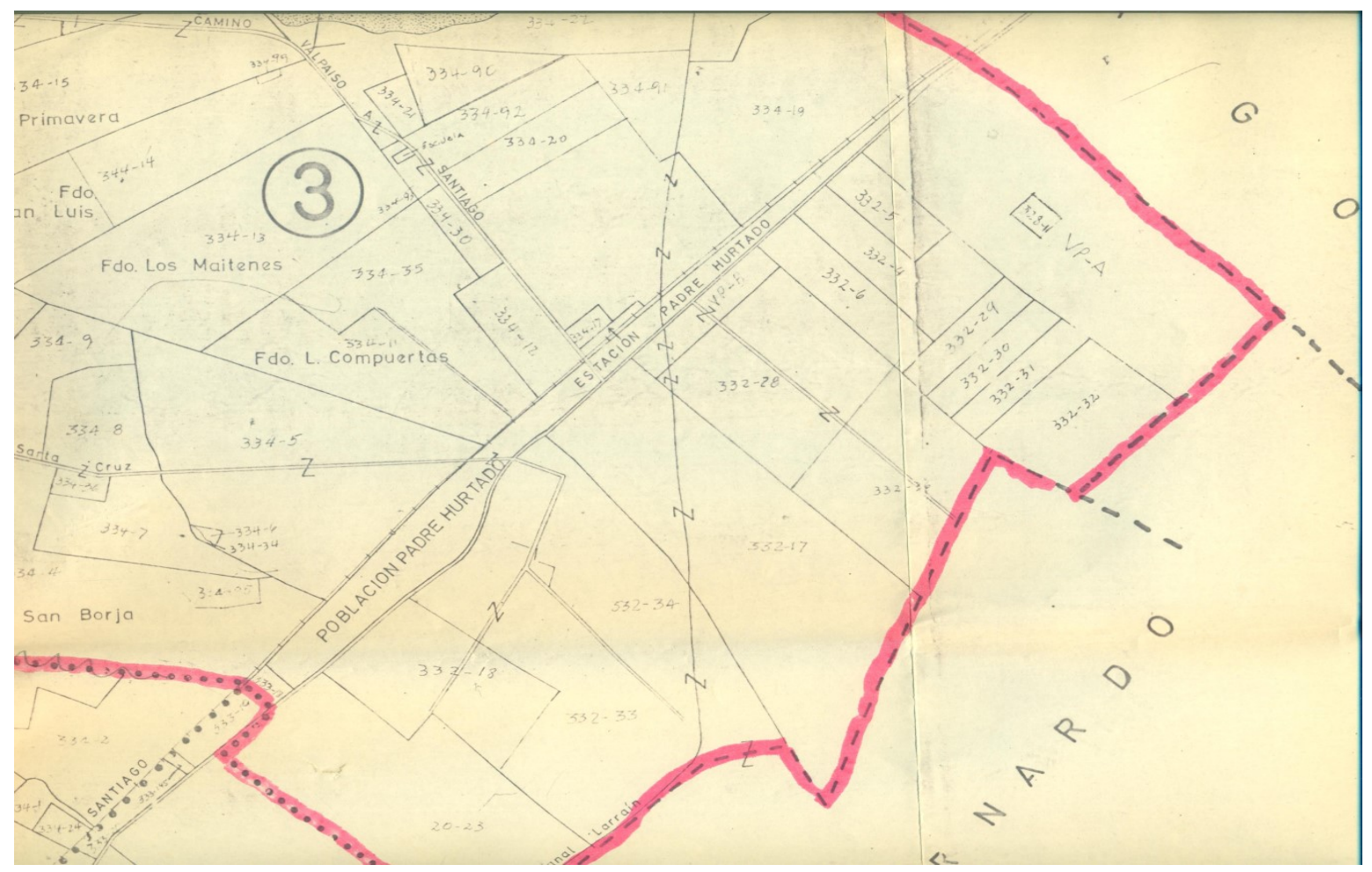

Subdelegación Padre Hurtado (antiguo Marruecos) de la comuna de Peñaflor, 1965. Escaneado y digitalizado por el autor.13

12 "Sesión municipal N5, 13 de julio de 1952". En Archivo Ilustre Municipalidad de Peñaflor.

13 Dibujo de Mario Vidal S., Municipalidad de Peñaflor, 1965. En UCMPH. 


\section{Un espacio de encuentro común en la localidad}

La preocupación de Alberto Tagle Ruiz por el bienestar de sus inquilinos lo llevó a ceder un terreno y construir una escuela modelo el 6 de noviembre de 1916 que luego donó al fisco. Dicha escuela desde sus orígenes se llamó "Escuela mixta №278". Para 1937 se contabilizaba un registro de alumnos (matricula, salud y edad, información del apoderado, oficio, domicilio), clasificación de los alumnos, boletín estadístico, material escolar, visitas al establecimiento, notas finales, cursos divididos en 6: Idioma Patrio (Lectura, escritura, redacción, gramática y literatura [esta no se pasaba]), Matemáticas (Aritmética, sistema métrico, geometría, contabilidad (esta no se pasaba), Estudio de la naturaleza (Zoología, botánica, física y química, higiene [desde 6ํㅡ básico], puericultura [ésta no se pasaba]), Educación social (Geografía, Historia, Educación Cívica), Idioma extranjero (esta no se pasaba), Religión y moral, Educación física, Educación manual (Trabajos manuales, labores, economía doméstica, agricultura o minería [solo en 6ํㅡ básico]), Educación artística (Dibujo, música y canto). De todos los cursos establecidos, cuatro no se pasaban, lo que nos habla de una cierta precariedad profesional para un establecimiento que solo llegaba hasta $6^{0}$ básico y que buscaba establecer una formación pensada principalmente en el trabajo agrícola. También se registran las actas de exámenes y principalmente las matrículas: 137 hombres-130 mujeres en 1937; 154 hombres-146 mujeres en 1938; 209 hombres-198 mujeres en 193914. Hasta 1942 la matrícula era de 400 alumnos aproximadamente, mostrando un crecimiento sostenido 15.

En el registro de las matrículas los principales oficios de los apoderados eran de agricultor, inquilino, mayordomo, lechera, dueña de casa, herrero, y en menor medida obrero, comerciante y administrador. Mientras que las principales direcciones de los domicilios eran el fundo El Descanso, fundo Marruecos, fundo Santa Cruz, Bajos de Santa Cruz, El Bosque, Santa Rosa, El Manzano, Estación16. Así, la escuela que en 1937 se ubicada en el fundo Santa Cruz, era nutrida esencialmente con la misma población de Marruecos. La escuela estaba rodeada de un paisaje verdoso y acompañado de unos cuantos pequeños ríos y animales que diversificaban el paisaje y con una mínima intervención humana materializada más allá de unas cuantas casas de adobe, los establos de los fundos, unas capillas, y una extensa línea del tren que conectaba a la ciudad de Santiago con Cartagena y San Antonio. Pero la escuela era dependiente del Departamento de Santiago y no de Talagante, su capital provincial más cercana y directa territorialmente. Hasta 1942, último año de la escuela como propiedad del Estado controlada desde la capital, no se registran actos

\footnotetext{
14 Registro escolar Nº1. 1937, 1938, 1939. En Archivo Escuela República Argentina (AERA), comuna de Padre Hurtado. 2-198.

15 Registro escolar $N^{\circ} 2.1940,1941,1942.60-70$.

16 Registro escolar $N^{\circ} 2.1940,1941,1942.2-73$.
} 
pensados para la comunidad más allá de los pensados para la misma escuela como los actos de inauguración de año o graduación de 6º básico. Esto hasta 1943 que la escuela cambió de sostenedor y control.

A partir de 1943, la escuela pasa a depender del Departamento de Talagante, Provincia de Santiago, lo que en primera instancia significó su cambio de nombre: "Escuela completa-coeducacional N 4" dirigida por Zoila Aymerich T.17 Los matriculados en 1943 eran 357 alumnos, repartidos entre 9 cursos, y solo los cursos 4ํㅜㄴ 5ํㅜ y $6^{\circ}$ básicos tenían una asistencia completa todo el día, mientras que los demás cursos solo asistían media jornada.

La escuela estaba compuesta por seis salas de clase, un gimnasio que no estaba completamente cerrado estando libre por el costado norte, unos servicios higiénicos que estaban en un mal estado denotando la "existencia de un pozo negro rebozando con continuos derrames, las tazas del baño están tapadas, en consecuencia, dentro de la escuela, el alumnado y el profesorado se encuentran en una situación insostenible", según comentaba la dirección de la escuela18. Un día normal de clases en la escuela $\mathrm{N}^{\circ} 4$ comenzaba en la mañana con la primera apertura a las 8:20 y la llegada de la directora y el profesor de turno, la segunda apertura comenzaba a las 8:40 con la llegada de los profesores, y la tercera apertura finalizaba con la revista de aseo matutino a las 8:50. La primera clase se realizaba entre las 9:00-9:40, la segunda clase entre las 9:50-10:35, la tercera clase entre las 10:50-11:30, y la cuarta entre las 11:40-12:20. Aquí terminaba la jornada de mañana para el $1^{\circ}$, $2^{\circ}$ y $3^{\circ}$ básico, mientras que el $4^{\circ}, 5^{\circ}$ y $6^{\circ}$ básico almorzaban en la misma escuela. A las 13:15 comenzaba la apertura de la jornada tarde con la llegada de la directora y el profesor de turno, a las 13:35 debían llegar los profesores y la clase comenzaba a las 13:45 y duraba hasta las 14:35, mientras que la segunda clase se realizaba entre las 14:40 y 15:30, la tercera se realizaba entre las 15:40 hasta las 16:20, y la última clase del día se realizaba entre las 16:30 y las 17:20. Las clases de religión eran realizadas por el Reverendo Padre Hernán Irrazabal19. El 28 de marzo de 1944 se contabilizó un registro de los materiales que se usaban en el colegio: "Llegó el material escolar que consiste en: 7 resmas de papel de dibujo, 700 cuadernos $n^{\circ} 2$ y 700 del $n^{\circ} 3,7$ cajas de tiza. El inmobiliario está bien conservado, solo en el $6^{\circ}$ básico falta un pizarrón" 20 . Se da también constancia de la necesidad de refaccionar la reja a la calle, renovación del piso del gimnasio y una pintura general a este mismo edificio² 1 . Recién el 11 de julio de 1947 se comenzó a llenar con asfalto

\footnotetext{
17 Registro escolar N³. 1943, 1944, 1945. 181.

18 Registro escolar N³. 1943, 1944, 1945. 182.

19 Registro escolar N³. 1943, 1944, 1945. 183.

20 Registro escolar $N^{\circ} 3.1943,1944,1945.184$.

21 Registro escolar N³. 1943, 1944, 1945. 185.
} 
el patio de la escuela22, lo que nos habla que gran parte de la modernización que tuvo la escuela, comenzó recién a partir de su dependencia bajo una administración más cercana.

En el registro de junio de 1944 se constata que en los días domingo los alumnos también iban a la escuela para reunirse a estudiar música. La vida dentro y fuera de la escuela era muy elástica para el infante que vivía en Marruecos. La escuela cumplía un rol social más allá de la mera educación sirviendo de fuerte apoyo para los apoderados con sus hijos. En junio de 1944, la escuela trajo un ropero escolar que costó $\$ 184$ pesos y lograron ser atendidos doce alumnos. También la escuela pagaba sesenta pesos por el envío de madera terciada para la enseñanza de carpintería. En 1946 se da constancia de que el almuerzo escolar se preparaba con leña donada del fundo Santa Cruz, y cuando esta se acababa, esta era comprada por la misma escuela23. En 1944 se da constancia de un extenso terreno de cultivo que era usado del fundo Santa Cruz, dedicado al jardín y a la planta de hortalizas. Pero la preocupación de la escuela iba más allá, el 4 de septiembre de ese mismo año se registra que la directora Zoila Aymerich llevó a ocho alumnos al servicio dental Ecuador "porque necesitaban atención urgentemente"24. Solo tres años después, se realizó un servicio dental al año durante tres días para todos los alumnos de la escuela25. Así pues, la precariedad de la vida rural y la pobreza familiar del campo se trataba de subsanar en algunos aspectos para el infante.

Por otro lado, el sábado 30 de marzo de 1935, el periódico semanal independiente "La Voz de Peñaflor", daba constancia que el candidato independiente a alcalde de la comuna de Peñaflor, el industrial Leonidas Alberto Lagunas Meza, domiciliado en calle Balmaceda 208 de la villa de Peñaflor y a cargo de Imprenta Lagunas y Quevedo Ltda., se encargaba desde 1932 de estrechar vínculos entre la municipalidad de Peñaflor y las escuelas de las subdelegaciones rurales, al gestionar los desayunos para los niños campesinos de las residencias lejanas y facilitando la entrega de labores de oficio (principalmente en su propia industria) para los peones que tenían a sus hijos en esas escuelas 26 .

En ese contexto, los registros escolares escritos por la dirección del colegio, constantemente nos hablan en un lenguaje que refleja expresiones de molestia, impotencia y dolor por la escasez de recursos y las dolencias del clima. En la primera mitad de la década de los cuarenta el gran problema para la escuela fue de índole sanitario e higiénico. En 1944 se da conocimiento de "un pozo negro ubicado en uno de los patios que se encuentra hundido en toda su parte superior, por lo que

\footnotetext{
22 Registro escolar N4. 1946, 1947, 1948. 195.

23 Registro escolar $\mathrm{N}^{\circ} 4.1946,1947,1948.192$.

24 Registro escolar N³. 1943, 1944, 1945. 192.

25 Registro escolar N4. 1946, 1947, 1948. 196.

26 “La Voz de Peñaflor", Año 1, Núm. 1, 30 de marzo de 1935, 4. AUCMPH.
} 
procura de un arreglo inmediato a cargo de personas técnicas en estos trabajos" 27. Los servicios higiénicos eran precarios, constatando ya en la década de 1940 problemas de saturación en los pozos sépticos e inundación en las salas de clases para el mes de agosto provocado por las lluvias y el desborde de los canales.

Sumado a lo anterior, el 8 de agosto de 1944 las autoridades del colegio mencionan:

Llevamos ya dos semanas de continuadas lluvias, y naturalmente la asistencia deja mucho que desear por lo cual el profesorado no puede desarrollar materias nuevas de enseñanza. Se envío una nota al sr. Inspector Provincial, solicitando revisión de servicios sanitarios, estos quedaron en mal estado después de la inundación de la escuela debido al desborde de canales de la localidad la noche del día 828 .

Pero los problemas no acabaron ahí, el 5 de agosto de 1945 hubo una inundación en la sala de cocina en toda su extensión con unos 30 centímetros de agua provocada por la lluvia; también hubo otras dependencias inundadas y se vuelve a mencionar la necesidad inmediata de reparar el pozo séptico. Al siguiente mes, el 28 de septiembre de 1945 nuevamente se da constancia de la mala situación del pozo y el peligro que constituye para la salud de los profesores y los alumnos. Sin duda alguna, el pozo representó el mayor problema de la escuela en toda la década, pero no era el único. Durante 50 años la escuela no tuvo alcantarillado, por lo que el agua era extraída del fundo Santa Cruz. En agosto de 1946 ya se constata escasez del agua, que en su mayoría era traída del fundo²9. En 1945 la necesidad de reparar el piso del gimnasio por estar despedazado también fue todo un problema. Al dar cuenta de la precariedad alimenticia de los mismos alumnos, en 1946 se repartieron 80 almuerzos diarios para niños priorizándose a los más desnutridos y a los que viven alejados de la escuela ${ }^{3}$. La cantidad de fallecimientos producto de una mala alimentación, una escasez en el uso de la medicina moderna como las vacunas, una higiene bien paupérrima y junto a la tempestad del clima que con las aguas contaminadas del tranque inundaba las salas, la cocina y desbordaba el pozo séptico, hicieron que las enfermedades bronco-pulmonares, resfríos, reumatismos y el cólera fueran de las más comunes y mortales para los niños. Miguel Verdugo fue testigo de este fenómeno: "Yo no me crie solo. La familia Verdugo fuimos 21 hermanos. Las circunstancias de la vida y en esos años la poca cobertura que hay aquí, eran puras mujeres, fueron falleciendo, la enfermedad las mató: la meningitis, después de que cayó todo ese lote caí yo, pero ya había en Santiago medicina para tratarla, por

\footnotetext{
27 Registro escolar N³. 1943, 1944, 1945. 193.

28 Registro escolar N³. 1943, 1944, 1945. 194.

29 Registro escolar $N^{\circ} 4.1946,1947,1948.194$.

3 o Registro escolar N4. 1946, 1947, 1948. 195.
} 
suerte le hice el quite a la meningitis"31. En pleno mes de fiestas patrias en 1947 una epidemia de meningitis azotó a la localidad por lo que en la escuela las vacaciones de septiembre se extendieron a todo un mes. Por este tipo de situaciones, bajo la dirección de Berta Segura Yáñez se organizó en 1946 la Cruz Roja32.

Los historiadores Gabriel Salazar y Julio Pinto exponen en una dimensión más totalizante lo difícil del entorno familiar para la vida de los infantes: "Los niños, por cierto, quedaron atrapados en la intersección de los opuestos movimientos de fuga de sus progenitores. Intersección saturada, sin duda, de violencia emocional y física" (Salazar y Pinto, 2002: 168). Así pues, la dualidad de la belleza del paisaje versus la pobreza campesina fueron elementos movilizadores de una "comunidad emocional" que a partir de 1943 interactuaba cada vez más con la escuela y se consolidaba como una comunidad social "en contacto cara a cara" (Plamper, 2014: 23).

Es inevitable que esta comunidad rural cayera dentro de los parámetros de una comunidad imaginada de Benedict Anderson (1993) en un periodo donde el nacionalismo aun golpeaba con fuerza al país. La escuela $\mathrm{N}^{\circ} 4$ sirvió como la condición de posibilidad de esta obra dentro de la localidad. Pues la conmemoración y la simbología entraron de la mano con el arte de la pedagogía con los niños relacionándolos con eventos que ocurrían muy lejos de sus hogares y de su diario vivir. Las primeras actividades ligadas a este tipo datan del 14 de abril de 1944 cuando se realizó el programa "Día de las Américas" donde cada curso representó a una nación. El 17 de abril se leyó en el acto matutino el mensaje: "El continente de la hospitalidad" dado por el ministro de Educación en la ciudad de Santiago, y el mismo día, en el acto de apertura al iniciar las clases, se conmemoró el aniversario de la fundación de la Universidad de Chile33. De esta forma, las primeras grandes actividades temáticas de la escuela, que se tiene registro, son relacionadas a eventos fuera de la misma localidad, principalmente relacionadas con Santiago. De esta manera, más allá del curso de "historia patria" e "historia universal" que se impartía en la escuela, las primeras actividades buscaban ponen en sintonía a una escuela que servía de puente con la localidad, pero al mismo tiempo con la capital y la nación.

Esas solo fueron las primeras actividades. Pues otro tipo de actividades se preocupaban por relacionar los mitos y acontecimientos históricos propios de un discurso de construcción nacional, como lo fue el 14 de julio de 1944 donde se realizó el "acto patriótico de conmemoración de la Batalla de la Concepción con la participación de toda la escuela". Solo un mes después, en un viernes 18 de agosto del mismo año, las profesoras Raquel Torres, Llaydeé Iturria y Estela Rivera

31 Entrevistado por el autor en 2017. Miguel Jesús Verdugo Araya, Comuna de Padre Hurtado, avenida San Pedro 207. AOMPH10.

32 Registro escolar N4. 1946, 1947, 1948. 190.

з 3 Registro escolar N³. 1943, 1944, 1945. 192. 
realizaron la colecta Pro-Santuario de la Patria recaudando la suma de 226,40 pesos a lo largo de toda la localidad; esta se envió al sr. Melo, secretario de la Municipalidad de Peñaflor ${ }^{4}$. Este hito marca el inicio de las intenciones de generar una primera obra conmemorativa de índole material. Esto es muy interesante puesto que la intención nacida en la escuela se buscó proyectar a lo largo de toda la localidad. Esto también viene a demostrar la capacidad de vinculo como ente mediador que posee la escuela con la misma municipalidad. Justo en un período en que, además, durante el mismo mes, el 26 de agosto se conmemoró el aniversario de la promulgación de la Ley de Instrucción Primaria Obligatoria.

El historiador Anthony Smith propone la noción de "naturalización de los sitios", esto es, los espacios pueden convertirse en parte del medio de cada comunidad y transformase en elementos de su hábitat natural y de sus paisajes imaginarios (Smith, 1998: 64). En ese sentido, se busca conferir un "carácter étnico a los panoramas", es decir, volver a los paisajes parte de la comunidad, convertirlos en propiedades y expresiones de un pueblo (Smith, 1998: 65). Con esto tampoco se puede desconocer que a pesar de que la escuela estaba ubicada en un fundo, en una zona ampliamente rural y con las condiciones higiénicas propias de una escuela colonial y del siglo XIX, la escuela, que constituía parte del imaginario paisajístico local, estaba muy en sintonía con los eventos tanto nacionales, como simbólicos imaginarios.

El 6 de septiembre de 1944 los equipos de Basquetbol del $2^{\circ}$ y $3^{\circ}$ básico jugaron por primera vez con los equipos de Peñaflor y Malloco. También, el 18 de septiembre en plenas fiestas patrias, se realizó el "Gran festival” en la escuela $\mathrm{N}^{\circ} 4$ en colaboración con la escuela $N^{\circ} 21$ (futura Escuela Julio Covarrubias) y del coro "Marruecos" dirigido por Manuel Tagle V. Con esto, también la escuela se consolidaba como sede para eventos dentro de la localidad y la comuna. En materia de deporte la escuela también sirvió de sede para campeonatos que abarcaban a todo el Departamento de Talagante. El 3 de diciembre de 1944, la escuela realizó un campeonato entre los equipos de la "Bata" de Peñaflor, donde los alumnos de la escuela $\mathrm{N}^{\circ} 4$ perdieron "pero por muy poca diferencia a pesar de que se han formado recientemente" 35 . Solo tres días después, la escuela fue visitada por el alcalde de la comuna don Ernesto Prado T. y el Inspector del $7^{\circ}$ sector don Andrés Aguayo 6 . La importancia de la escuela con la localidad, sin duda fue un incentivo para que las máximas autoridades de la comuna visitaran la escuela al cerrar el año escolar, y más significativo es en un espacio plenamente rural y no urbanizado, como sí sería, en cambio, el caso de Peñaflor. Gran parte de las actividades y la labor emprendida en la escuela se debió a partir de que hubo un cambio a nivel de dirección una vez

\footnotetext{
34 Registro escolar N³. 1943, 1944, 1945. 193.

35 Registro escolar N³. 1943, 1944, 1945. 195.

${ }_{3} 6$ Registro escolar N³. 1943, 1944, 1945. 197, 198.
} 
que la escuela pasó a depender de Talagante, por ello la Municipalidad de Peñaflor el 31 de diciembre de 1944 reconoció esta labor cuando: "La directora [Zoila Dymerich Toro] recibió una nota de la Municipalidad en la que se le comunica con la suma de \$500 por la labor social y educativa desarrollada en la escuela de su cargo"37.

Pero la escuela no se encerraba solo en las actividades antes descritas. El libro de registro escolar da cuenta de uno de los rituales bien particulares que la escuela tuvo con los alumnos que cumplían el último año académico de la escuela. Se constata que el 16 de diciembre de 1945: "El profesorado ha despedido al $6^{\circ}$ año con un paseo a Cartagena [en tren]"38. Y solo unos días después, para las fiestas de navidad, la escuela cumplía su último rol con la localidad en el año, donde el 25 de diciembre "se repartieron juguetes a los niños de la escuela y a los no escolares, los carabineros ayudaron a mantener el orden"39. De esta manera, la estación Marruecos, la parroquia y la escuela " $\mathrm{N}^{\circ} 4$ " posicionadas en el centro de la localidad, se constituyeron como un espacio triangular de la ritualidad local.

Por otro lado, la escuela, nuevamente en sintonía con los acontecimientos nacionales, da constancia de que el 24 de junio de 1946 se declaró feriado escolar por el onomástico del presidente de la República Juan Antonio Ríos, y el 27 y 28 de junio también feriado por duelo nacional. Casi dos meses después, el 20 de agosto de 1946 se tiene registro de como seguía la situación con la colecta para el "ProSantuario de la Patria" donde se da una constancia de una nueva suma de $\$ 351,40$ pesos, mientras que, en el mismo mes, se hicieron dos unidades temáticas en toda la escuela: "Estados Unidos" y "Bernardo O'Higgins"40. Otro tipo de actividades que la escuela realizaba como sede, se atestigua como registro el 12 de octubre de 1946, donde se hizo la fiesta del libro organizada por el Rotary Club de Peñaflor 4.

El último registro escolar en dar cuenta de la vida escolar termina en 1948. Por ende, lo que sucede después, al igual que lo que sucede antes de 1937, es en gran medida una incógnita. Una de las últimas actividades registradas muestra a la escuela $\mathrm{N}^{\circ} 4$ como lugar seleccionado para inaugurar la primera cancha de básquetbol el 26 de octubre de 1947 por iniciativa y esfuerzo del coronel del Ejército Elias Ducand42. Esto era un paso más allá de la modernización para un deporte que tampoco es de origen nacional. Y la última actividad registrada corresponde al 20 de julio de 1948 donde por fin se inauguró el "Santuario de la Patria" materializado en una placa de metal ubicada en la sala de tercer año en homenaje a Bernardo 0`Higgins que costó \$300. Esto además fue acompañado de un

\footnotetext{
37 Registro escolar N³. 1943, 1944, 1945. 199, 200.

38 Registro escolar $N^{\circ} 3.1943,1944,1945.202$.

з 9 Registro escolar $N^{\circ} 3.1943,1944,1945.203$.

40 Registro escolar N4. 1946, 1947, 1948. 195.

41 Registro escolar N4. 1946, 1947, 1948. 198.

42 Registro escolar N4. 1946, 1947, 1948. 202.
} 
acto literario-musical en homenaje al personaje histórico43. Las palabras de la historiadora Barbara Rosenwein son elocuentes en mostrar lo que sería uno de los aspectos condicionantes de una comunidad emocional: "The physical and mental capacity to have emotion is universal, but the ways those emotions are themselves elicited, felt, and expressed depend on cultural norms as well as individual proclivities [...] Emotions depend on language, cultural practices, expectations, and moral beliefs" (Rosenwein, 2002: 836-837). Así pues, las emociones dentro de la comunidad escolar, en prácticas culturales y en un lenguaje particular, a partir de los registros, atestiguan una fuerte relación con la noción de nacionalidad y con las penurias propias de un espacio que aún estaba anclado socialmente en la premodernidad.

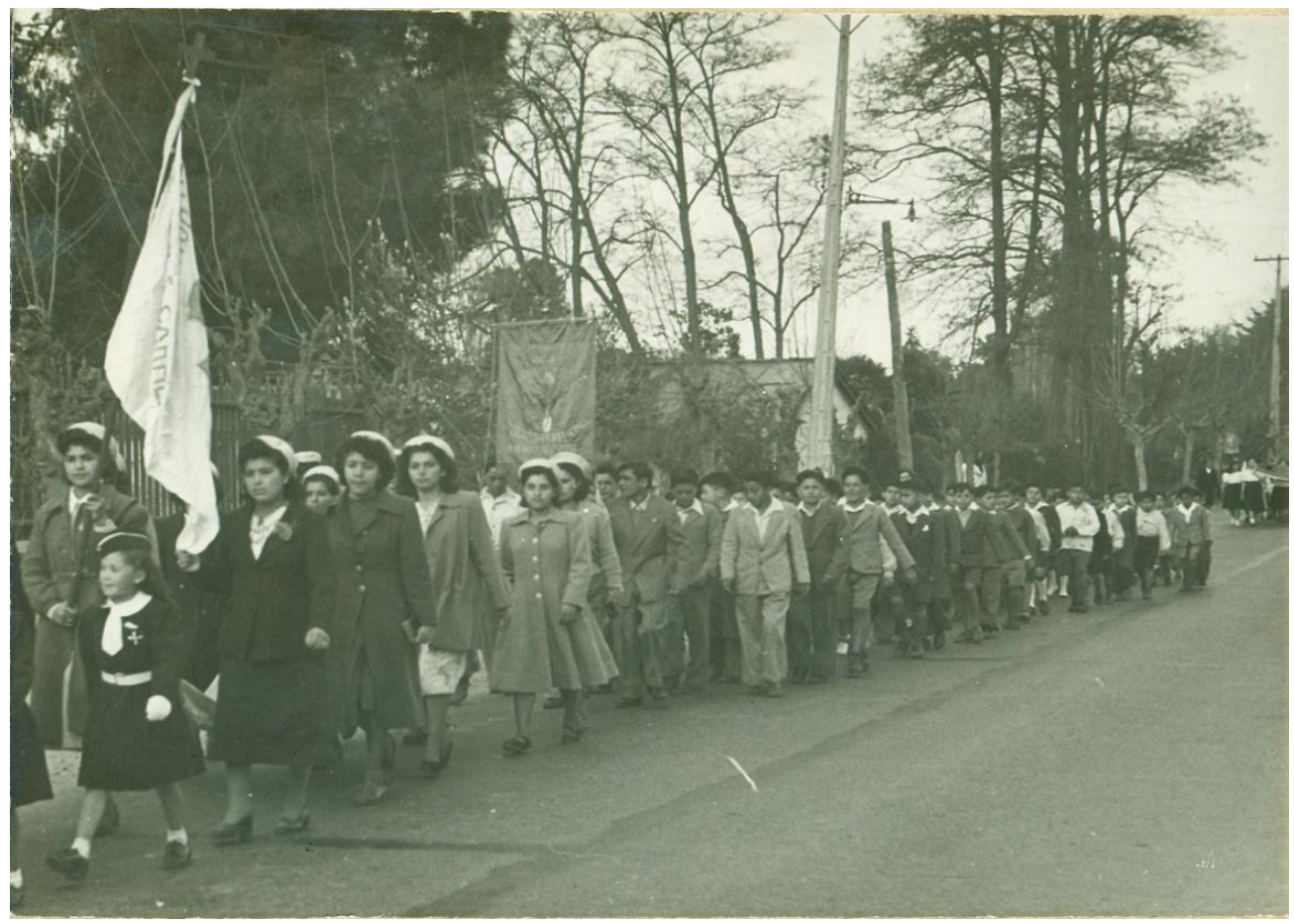

En la foto: Peregrinación del 8 de diciembre de 1943, Hijas de María y Acción Católica. En Archivo Municipalidad de Padre Hurtado.

43 "Registro escolar N4". 1946, 1947, 1948. 203. 


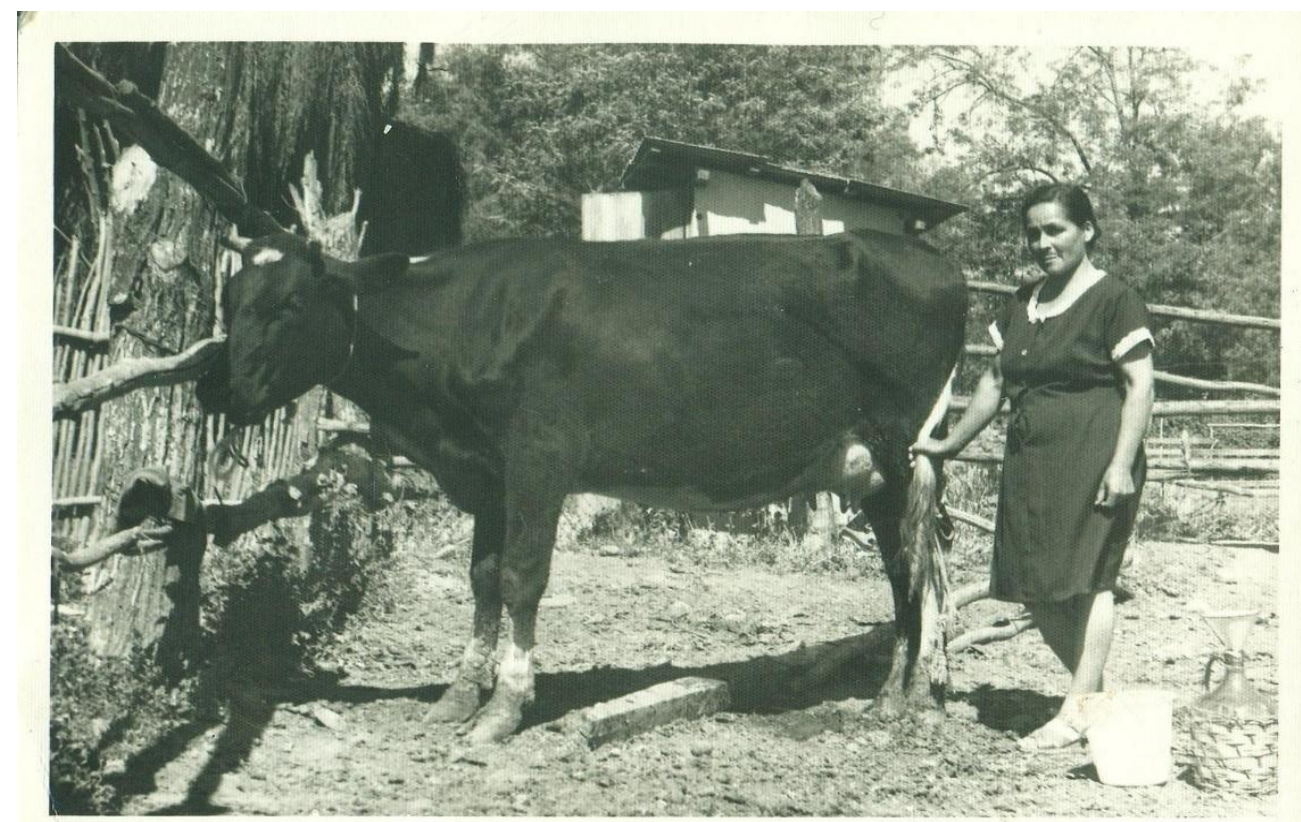

En la foto: Eudocia Contreras trabajando en el Fundo el Zotillo como lechera, vecina a la Escuela $N^{\circ} 4,1970$. Aporte de Familia Eudocia Contreras.

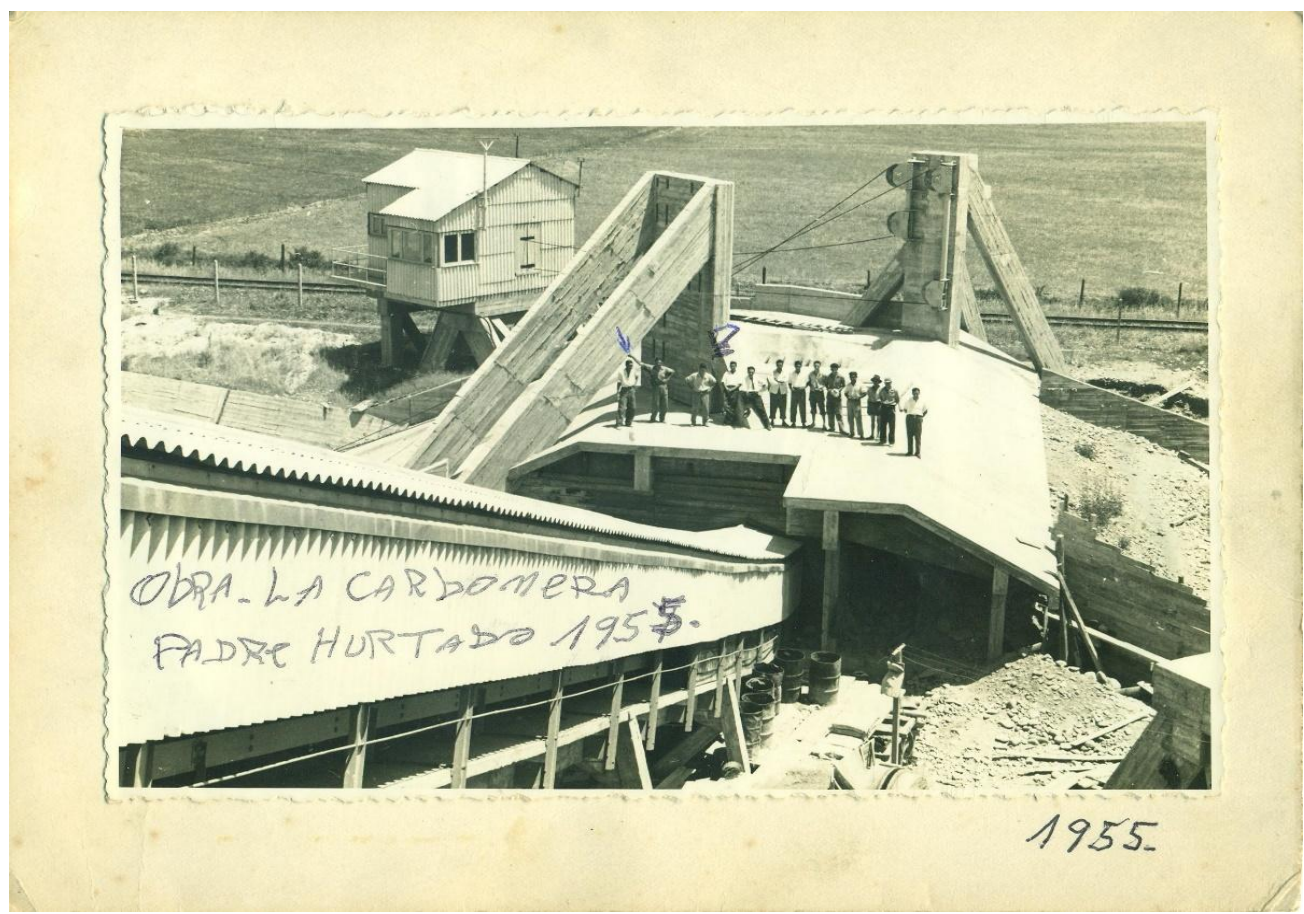

En la foto: La Carbonera de Padre Hurtado, a un costado del Camino a Melipilla, 1955. El obrero señalado frente a la arquitectura industrial es Héctor Eduardo Chacón Quiroz, padre de José Oscar Chacón Valenzuela, dueño de la foto. 


\section{Reflexiones finales}

La Plaza Santa Rosa de Chena se convirtió en cierto modo, en un punto neurálgico de desarrollo. Fue en ella donde nació la tenencia de carabineros en 193244, la Quinta Compañía de Bomberos en 1968 y el primer centro policlínico. Verdugo, que hasta el día de hoy habita la localidad y ha construido un importante espacio de experiencia al ser testigo de sus transformaciones, recuerda a esta zona como uno de los puntos predilectos de reunión: "De esta parte lo más concurrido que había, era un policlínico que está detrás del retén de carabineros, esa era apenas una casuchita chica donde había tres, cuatro carabineros y un médico, paramédico que era otra casuchita, de ahí para adelante todo cambió para nosotros"45. Con 2.892 almas en toda la localidad, el 1 de mayo 1961, un grupo de familias procede a tomarse una franja de terreno en las proximidades de las carboneras de Padre Hurtado, específicamente en los terrenos del predio Santa Rosa de Chena (Bustos Valdivia, 1997: 112, 115). Estas tomas de terreno fueron los primeros indicios de tensión y crítica social dentro de Padre Hurtado comenzando una nueva emocionante etapa histórica que está fuera de los límites de este estudio. Por otro lado, con servicios institucionales como un centro médico, una tenencia de carabineros, un cuerpo de bomberos y una escuela para la formación primaria, en los sesenta es claro establecer a Padre Hurtado con todas las características de una localidad en proceso de crecimiento urbano.

Previo al despertar campesino de la reforma agraria, la localidad rural, y específicamente la escuela representaron la comunidad. Una comunidad que es bien elástica, que se tiende a proyectar más allá de unos espacios. Es a través de los libros de registro escolar y la revisión de documentos municipales y otras fuentes locales que se ha logrado reconstruir parte del habitar semi rural, sus penurias, pero también sus esfuerzos por sortear una situación social de pre modernidad. Ya desde la década de 1940 se presentan ciertas condiciones de posibilidad de apertura para la localidad, dadas en cierta medida por el limitado desarrollo industrial del Estado que se materializó en una carbonera y cristalería que se instaló frente al camino a Melipilla y vecina a la línea ferroviaria y a la estación Marruecos. Es frente a la línea ferroviaria donde se han proyectado una multiplicidad de espacios pequeños para el habitar y es también el lugar donde se han dado las condiciones para resignificarlos ritualmente. Por ello, las interacciones gestadas en la escuela también responden y se enmarcan en un proceso mucho más complejo y de apertura con la localidad. La escuela " $\mathrm{N}^{\circ} 4$ " representó un punto neurálgico de resistencia a la situación de pobreza vivida en la subdelegación cuando esta pertenecía a Peñaflor. Junto a ella, la escuela " $\mathrm{N}^{\circ} 21$ " (futura Escuela Julio Covarrubias, extinta en la actualidad), fueron las

\footnotetext{
${ }_{4}$ Acta de creación de la Tenencia de Carabineros, Santa Rosa de Chena, Padre Hurtado. AUCMPH.
}

45 Miguel Jesús Verdugo Araya, Padre Hurtado, avenida San Pedro 207. AOMPH10. 
únicas escuelas en toda la zona durante la primera mitad del siglo XX, pero es en la "N4" donde se realizaron gran parte de los actos cívicos tanto para la subdelegación, como en algunas ocasiones, para toda la comuna. En 1958 la escuela registró un peak de 737 niños matriculados convirtiendo al establecimiento con más alumnos en toda la localidad, y en 1965 se convirtió en la primera escuela de toda la subdelegación en impartir el $7^{\circ}$ año, lo que viene a confirmar la preponderancia de la escuela en la historia de Padre Hurtado, antigua Marruecos.

Las limitaciones, fisuras, silencios no intencionados presentes en este estudio son solo una prueba de que todavía queda mucho por explorar. Una deuda para el porvenir que con gusto es asumida.

\section{Fuentes}

Archivo Unidad de Cultura Municipalidad de Padre Hurtado (AUCMPH). Archivo Oral Municipalidad de Padre Hurtado (AOMPH). Biblioteca Nacional de Chile. Archivo Escuela República Argentina (AERA). Archivo Municipalidad de Peñaflor. Archivo personal del autor.

\section{Bibliografía}

Bengoa, J. (2015): Historia rural del Chile central. Crisis y ruptura del poder hacendal. Tomo II. Santiago de Chile, LOM Ediciones.

Bustos Valdivia, H. (1997): Peñaflor, Malloco y Padre Hurtado...Una historia de 5 siglos. Peñaflor, Ilustre Municipalidad de Peñaflor.

Darley, G. (2010): La fábrica como arquitectura: Facetas de la construcción industrial. Barcelona, Editorial Reverté.

Plamper, J. (2014): "Historia de las emociones: caminos y retos", Cuadernos de Historia Contemporánea, 36, pp. 17-29.

Rosenwein, B. H. (2002): "Worrying about Emotions in History", The American Historical Review, 107(3), pp. 821-845.

Salazar, G. y J. Pinto (2002): Historia Contemporánea de Chile, Vol. 5, Niñez y juventud. Santiago de Chile, LOM Ediciones. 
Smith, A. (1998): "Conmemorando a los muertos, inspirando a los vivos. Mapas, recuerdos y moralejas en la recreación de las identidades nacionales”, Revista Mexicana de Sociología, 60, pp. 61-80.

Wirth, L. (2005): “El Urbanismo como modo de vida”, Bifurcaciones, 2, pp. 1-15.

Fecha de recepción: 1 de marzo de 2021

Fecha de aceptación: 30 de abril de 2021 